\title{
Evaluation of possums sleep intervention: A pilot feasibility study
}

\author{
Lia Closson ${ }^{1}$, Marjo Flykt ${ }^{1,2,3}$, Zeynep Biringen*1 \\ ${ }^{1}$ Department of Human Development and Family Studies, Colorado State University, USA \\ ${ }^{2}$ Faculty of Social Sciences/Psychology, Tampere University, Finland \\ ${ }^{3}$ Faculty of Medicine/Psychology, University of Helsinki, Finland
}

Received: July 26, 2019

DOI: 10.5430/jnep.v10n2p15
Accepted: October 8, 2019

Online Published: October 29, 2019

\begin{abstract}
The first year with a child is one of the most challenging times for mothers due to repeated awakenings typical for young infants. Research has shown that persistent fragmented sleep increases a mother's risk for low overall well-being, which can challenge the mother-infant relationship. In an effort to improve sleep for both mother and infant, healthcare providers often recommend infant behavioral sleep interventions. The primary focus of this pilot study was to assess the feasibility of the Possums Sleep Intervention, a psychoeducational group workshop for women with infants between the ages of 0-6 months. A second goal of the study was to evaluate the potential of the Possums curriculum in improving maternal and infant sleep and self-reported mother-infant emotional availability. Participants were 24 mothers with their 0-6 month old infants assessed at the start of the study and again at the completion of the 4-week workshop. Results showed improvements in the perceived emotional availability in the mother-infant relationship; however, positive effects related to maternal or infant sleep were only on a trend level.
\end{abstract}

Key Words: Infant sleep, Infant sleep intervention, Mother-infant interaction, Emotional availability

\section{INTRODUCTION}

The first year after the birth of a child is one of the most challenging times for a woman in terms of her sleep. Due to her infant's ever-changing sleep and feeding schedules, a mother often experiences fragmented sleep due to frequent disruptions. ${ }^{[1]}$ Fragmented sleep is associated with impaired cognitive and emotional functioning, ${ }^{[2,3]}$ decreased sleep quality, ${ }^{[4]}$ increased stress and depression, ${ }^{[4-7]}$ and parenting problems such as lower emotional availability to the child's needs. ${ }^{[8]}$

In an effort to support mothers and infants as they navigate the first year of infant sleep, two theories have emerged on infant sleep management. The first is grounded in oper- ant conditioning theory where behavioral interventions are used to modify the infant's biological sleep patterns. ${ }^{[9]}$ The second is founded on evolutionary theory, where disrupted infant sleep is viewed as normative and biologically adaptive. Therefore, it is believed that teaching parents about child development, as it pertains to sleep, will help parents accept sleep disruptions as a part of normative development. ${ }^{[10]}$ The two philosophies are discussed below in more detail.

\subsection{Behavioral sleep interventions}

Sadeh, Tikotzky, and Scher ${ }^{[11]}$ view infant sleep through a transactional model: that there is a bi-directional link between parental nighttime behaviors and infant sleep.

\footnotetext{
* Correspondence: Zeynep Biringen; Email: Zeynep.biringen@ colostate.edu; Address: Department of Human Development and Family Studies, Colorado State University, USA.
} 
Whereas parental nighttime routines can influence infant sleep patterns, infant temperament also influences how actively involved parents are in supporting their child in falling asleep.

B.F. Skinner ${ }^{[12]}$ considered sleep a behavior that can be conditioned through the use of positive and negative reinforcement. Studies have consistently supported these views. Infants with parents who are actively involved (e.g., rocking, feeding, holding) in supporting them fall asleep are more likely to experience an increase in both number and duration of nighttime awakenings than infants whose parents consistently practice a more hands off approach. ${ }^{[13-16]}$ Skinner's principles can be seen in contemporary behavioral infant sleep interventions, which aim to decrease the number and duration of nighttime awakenings by reducing parental support, thus teaching the infant to self-soothe when falling asleep. Parents are often recommended from the beginning to implement one or a combination of the following interventions: delayed parental response to infant cues, initiated feed-play-sleep cycles, and adherence to sleep algorithms. ${ }^{[17,18]}$

Delayed parental response. To teach infants to self-soothe at bedtime, parents delay responding to their infant's cues (e.g., crying or calling out) in either complete or graduated extinction. ${ }^{[19]}$ In complete extinction, the infant is placed in bed at a designated time each night and parents do not return until morning regardless of the infant's distress. In graduated extinction, parents wait for a specified time (e.g., 5 minutes) before responding to their infant's cries, and the time is gradually increased. Child's age, temperament, and parent's ability to tolerate infant crying dictate response times. As overly attentive parental interactions are thought to reinforce undesired infant behaviors, parental responses usually last between 15 seconds and 1 minute with minimal parent-child interaction. ${ }^{[18,19]}$ Opponents of the extinction method are concerned that ignoring an infant's crying cues is inconsistent with sensitive parenting. ${ }^{[20]}$ Also many parents fail to comply with behavioral interventions, ${ }^{[18]}$ due to stress or fear of detrimental effects on either the child or the parent. ${ }^{[21]}$

Feed-play-sleep cycles. Similar to delayed response, feedplay-sleep cycles aim to teach the infant to self-soothe as s/he falls asleep in a solitary sleep environment. The goal is to separate the connection between sleep and physical contact with the parent, including feedings, ${ }^{[20]}$ which are considered as inappropriate learned stimulus cue for sleep. Instead, infants are taught to associate other stimuli with sleep, e.g., bedtime routines. Parents are instructed to create a routine in which the infant, upon waking, is fed, then engaged in stimulating play, and finally, is put down to sleep without parental support. The theory is that if infants have a routine, they learn to expect that sleep follows play and therefore, will not need parental assistance. Opponents suggest that falling asleep while feeding is not a learned behavior, but rather a biologically driven phenomenon associated with the activation of the parasympathetic nervous system and elevated levels of oxytocin and plasma cholecystokinin after a feeding. ${ }^{[17,20]}$ It is suggested that separating sleep from feeding can increase the arousal of the sympathetic nervous system and the hypothalamic-pituitary-adrenal system which can create inconsolable crying for the infant. ${ }^{[20]}$

Sleep algorithms. Sleep algorithms are statistical averages that dictate recommendations on infant sleep patterns within a 24-hour period. ${ }^{[20]}$ Health care providers encourage parents to adhere to the recommended sleep algorithms. The suggested amount of sleep varies from study to study. One study found that the normal range of infant sleep within a 24-hour period is $9.3-20$ hours $(\mathrm{M}=14.6)$ for a $0-2$ month old infant, 9.4-17.8 hours ( $\mathrm{M}=13.6)$ for a 3-month old, and 8.8-17 hours $(\mathrm{M}=12.9)$ for a 6-month old. ${ }^{[22]}$ Another study categorized infant sleep development into three stages: duration of the longest sustained sleep period, the duration of the longest self-regulated sleep period, and the infant's ability to sleep through the night. ${ }^{[23]}$ According to the authors, a 6-month old infant can sustain uninterrupted sleep for eight hours and 9-month olds for nine or more hours. However, estimates and recommendations differ and do not always take into account individual variability. For example, the American Academy of Pediatricians' (AAP, 2014) recommendation of 16-17 hours of sleep within a 24-hour period fails to disclose the full range of normative sleep; therefore, a parent of a healthy 2-month old infant who sleeps only 10 hours in a 24-hour period may be unnecessarily concerned. Whittingham and Douglas ${ }^{[20]}$ suggest that algorithms put an infant at risk for developing sleep issues as they may suggest longer sleep hours than the infant biologically needs, and teach him to rely on external rather than internal cues to induce sleep.

Although behavioral sleep interventions are associated with moderate improvements in infant nighttime sleep duration in some studies, ${ }^{[24,25]}$ other studies indicate that they are ineffective in improving maternal and infant sleep, ${ }^{[26]}$ or in protecting maternal well-being. ${ }^{[26-28]}$

\subsection{Infant sleep issues as normative}

In response to these concerns, some researchers have suggested an alternative paradigm to infant sleep; that night awakenings and erratic daytime sleep patterns are normative and biologically adaptive and frequent arousals serve as an evolutionary based survival mechanism. ${ }^{[10,29-31]}$ For example, a newborn's stomach capacity is very limited 
and frequent feedings are thus necessary. ${ }^{[10,32]}$ Frequent arousals may also protect from Sudden Infant Death Syndrome (SIDS), as they keep the infant from falling into deep sleep. ${ }^{[10,33]}$

Normative developmental progression creates disequilibrium within the infant's system and can thus also affect infant sleep patterns. ${ }^{[10]}$ For example, an infant may start to wake again at night when learning to crawl or experiencing separation anxiety. Proponents also suggest that the perception that frequent night awakenings and erratic daytime sleep are problematic is a socially constructed concept. ${ }^{[30]}$ When parents are given realistic information on normative infant sleep and its biologically driven development, they may be more able to accept their infant's sleep behaviors. ${ }^{[29]}$

Although this approach addresses some of the concerns associated with behavioral sleep interventions, it does not empathize with parents' basic need for restorative sleep or selfcare. ${ }^{[20]}$ What is missing from contemporary infant sleep paradigms is an interdisciplinary prevention strategy that recognizes and is sensitive to the needs and well-being of both the mother and the infant while also protecting the motherinfant relationship.

Developers of the Possums Sleep Intervention attempt to address this gap by incorporating important concepts from developmental psychology, medical science, lactation science, evolutionary science, emotional availability theory, and acceptance and commitment therapy to support healthy sleep and well-being for mothers. ${ }^{[20,34]}$ The Possums Sleep Intervention does not solely focus on changing infant sleep patterns but rather emphasizes the development of maternal knowledge and skills to increase her acceptance of normative infant sleep patterns while also minimizing nighttime disruptions. It further encourages mothers to create enjoyable and meaningful lives despite sleep challenges while also embracing a mindset that promotes positive mother-infant relationships. A prior qualitative study ${ }^{[35]}$ in Australia found that the intervention was acceptable to parents, and highly valued. Recipients reported reduced stress, less concern about perceived sleep problems (frequent night-awakenings, short-day-time naps, delayed sleep onset), and better quality of life.

To our knowledge, this is the first study to conduct the Possums Sleep Intervention in a group format (with a permission from the developers) and also the first with a quantitative, empirical evaluation component to the implementation. Due to the pilot nature of the study, we first wanted to assess the feasibility of easily recruiting for, adequately delivering, and sufficiently retaining participants in Possums and secondarily to evaluate its potential in improving maternal and infant sleep, and reported emotional availability in mother-infant relationship. No control group was used in the pilot phase.

\subsection{Research questions and hypotheses}

1) Does the intervention improve maternal and infant sleep patterns, i.e., decrease maternal sleep disturbances and increase sleep adequacy and sleep quantity, and improve her perceptions of infant sleep? We hypothesize that there will be within subject improvements between pretest and posttest assessments in all areas.

2) Does the intervention improve emotional availability in the mother-infant interaction? We hypothesize that participants will report improvements in the emotional quality of their relationship with their child

\section{METHOD}

\subsection{Participants}

Fifty-eight women responded to recruitment flyers describing the study that were placed at local pediatric clinics, birth and postpartum doula offices, new parent support groups, breastfeeding support groups, clinical breastfeeding clinics, and social media over a 14-month time period. Inclusion criteria required that infants be singletons, between the ages of 0-6 months at the beginning of the first workshop and mothers be English speaking. Compensation for participation in the study was not offered. After receiving more information regarding the study, 24 mothers $(41 \%)$ decided to participate. Of the committed participants, only two $(8.3 \%)$ did not complete the full study. Given that we approached the study with "an intention to treat" mindset, we analyzed all data that was available $(\mathrm{N}=24)$. Sixty-seven percent of the infants were male and $74 \%$ were first-born. Approximately $92 \%$ of the participants identified as Caucasian with the remaining $8 \%$ identifying as either Latina or Indian. At intake, maternal ages ranged from 22-38 years of age $(\mathrm{M}=30, \mathrm{SD}=4.2)$ and infants' ages from 2-28 weeks $(\mathrm{M}=12.4, \mathrm{SD}=7.0)$. All participants were either married (92\%) or in a relationship and living with their partner (8\%). All mothers had attended college, with $42 \%$ having a bachelor's degree and $38 \%$ holding graduate or higher degrees. The annual household incomes ranged from $\$ 40,000$ to over $\$ 100,000$. In terms of infant sleep arrangements, $33.3 \%$ of the infants slept in bed with their parents, $33.3 \%$ slept in a crib in the parents' room, $25 \%$ slept in a crib in a separate room, and $8.4 \%$ cited that the infant began the night in a crib in his/her own room and moved to the parent's bed with the first feeding.

\subsection{Procedure}

Possums is a psychoeducational group workshop delivered over four consecutive weeks in 1.5-2-hour segments to mothers with infants between the ages of 0-6 months. Through 
discussions on parenting values, responsive caregiving, sleep hygiene, relaxation, and mindfulness, mothers are empowered to create individualized lifestyle plans that promote healthy sleep practices, thereby, improving maternal and infant well-being. ${ }^{[20]}$ All workshops were facilitated by the same group leader.

Session 1: Empowerment. The focus of Session 1 was to facilitate a relationship between the group leader and the participants, based on trust, empathy, and empowerment. Each mother had an opportunity to share her perceptions of her infant's sleep. Participants were introduced to the concept of their own expertise related to the infant, whereas the facilitator put herself in the position of a "fellow traveler"[31] rather than the expert. The facilitator's role was to teach mothers the latest evidence about sleep so they could create personalized solutions to promote healthy sleep and lifestyle. Identifying personal parenting values was a key component of Session 1.

Session 2: The facts about sleep. Session 2 aimed to teach mothers that falling asleep is not under conscious control, but rather, is regulated by sleep-inducing hormones and the circadian pacemaker. Although people cannot consciously fall asleep at any given moment, the Possums Sleep Intervention aimed to help mothers create a lifestyle that would promote healthy sleep patterns. Mothers were also taught that sleep is dynamic and variable, changing from day-to-day. Possums Sleep Intervention helped mothers to understand individual variability in infant sleep and discouraged comparisons between their and another mother's baby. Reducing barriers to healthy sleep was also a focus of Session 2. A discussion on the importance of the downregulating sympathetic nervous system and its impact on sleep efficiency was incorporated into the curriculum. Furthermore, sleep safety issues such as SIDS were discussed.

Session 3: Action. During Session 3, mothers were taught how simple lifestyle changes can enhance their sleep and therefore, their well-being. The role of natural environmental cues for their circadian pacemaker was discussed. A conversation on how cognitive diffusion negatively affects a mother's sleep efficiency was also part of the intervention. Rather than ruminating about how tired they are going to be in the morning due to infant nighttime awakenings, mothers were encouraged to focus their attention on positive aspects of their lives. Relaxation was an important concept in Session 3. To help alleviate stress and to create a more relaxing evening, mothers were encouraged to participate in a physical activity by themselves or with their infants as well as to incorporate enjoyable and sensory rich activities to their daily routine to help them live a meaningful life.
Session 4: Check-in. Session 4 was a check-in session to evaluate the effectiveness and feasibility of each mother's personal lifestyle plans.

\subsection{Measures}

Measures were completed using the online survey platform, Qualtrics. All measures were administered prior to intervention and again after completing it.

Maternal sleep patterns. The Sleep Scale from the Medical Outcomes Study (MOS Sleep Study ${ }^{[36}$ ) is a 12-item, self-administered tool that assesses adult perceptions of their sleep initiation, maintenance, respiratory issues, quantity, perceived adequacy and desire for sleep. ${ }^{[37]}$ The scale ranges from 1 (all of the time) to 6 (none of the time). Sample questions include "How long did it usually take for you to fall asleep during the past 4 weeks," "How often during the past 4 weeks did you get enough sleep to feel rested upon waking in the morning," and "How often during the past 4 weeks did you feel drowsy or sleepy during the day?" In terms of internal reliabilities, the MOS Sleep scales were adequate: sleep disturbance (.80), sleep adequacy (.76), daytime somnolence (.63) and sleep problems (.78). ${ }^{[36]}$ This project focused on three specific domains: sleep disturbances (difficulty in falling asleep, length of time to fall asleep, restless sleep, waking up during sleep and having difficulty in falling asleep again; higher values representing less sleep disturbance, i.e., better sleep quality), sleep adequacy (feeling rested upon waking in the morning, getting the amount of sleep needed; higher values representing less sleep adequacy, i., poorer sleep quality), and quantity of sleep (number of hours).

Maternal perceptions of infant sleep. Maternal perceptions of infant sleep were measured with one question from the Brief Infant Sleep Questionnaire (BISQ ${ }^{[38]}$ ), "Do you consider your child's sleep as a problem", on a 3-point scale (1 $=$ a very serious problem, $3=$ not a problem at all).

Emotional availability. Emotional availability was assessed using a 36-item Emotional Availability-Self Report (EA$\left.\mathrm{SR}^{[39]}\right)$, scored on a 5-point scale $(1=$ Not agree at all -5 $=$ totally agree). This assesses parental perception of the emotional quality in the relationship with their child. The subscales include mutual attunement, child involvement with parent, affect quality, intrusiveness, and hostility. Sample items include "I like to have eye-contact with my child," "By using his/her body language, my child is able to show me he/she wants to play, talk, or interact," and "I wonder whether my child enjoys my presence." Items are scored on a 5-point Likert scale ranging from "not agree at all" to "totally agree." For all subscales except affect quality, internal reliabilities 
range from .71 to .84 ; affect quality is $.49 .{ }^{[40]}$

\subsection{Analytic strategy}

Missing values were replaced with Expectation Maximization (EM). To answer our research questions, whether there was change from pre- to post-intervention in maternal sleep patterns, maternal perceptions of infant sleep, and emotional availability, three Repeated Measure Ancovas with univariate tests for significant main effects were conducted. Infant age was used as a covariate in all analyses, as it may affect sleep patterns.

\section{Results}

\subsection{Feasibility analysis}

Recruitment turned out to be more challenging than we had originally anticipated, taking 14 months. The primary explanation given for not participating was pre-existing family or work commitments. However, among participants, attrition was low $(8.3 \%)$, indicating that those committed remained in the intervention. One participant with a 3-week old infant withdrew from the study while completing the initial assessment, due to difficulties in committing time while still in the process of establishing a nursing and sleep routine with her infant.

The study design did not include an objective measure to assess ratings of participant engagement. However, participation in the sessions was extensive and attendance and time log indicated impeccable and prompt attendance. The women actively participated in group discussions, they rarely missed a class and when one was missed, they were willing to schedule a make-up session prior to the next class.

\subsection{Descriptive statistics}

Table 1 shows means, standard deviations and observed ranges of the study variables.

Table 1. Means, standard deviations and observed ranges of the study variables

\begin{tabular}{|c|c|c|c|}
\hline & $\mathbf{M}$ & SD & Observed range \\
\hline \multicolumn{4}{|l|}{ Maternal and infant sleep variables } \\
\hline Maternal sleep adequacy (pre-test)* & 67.50 & 21.11 & $(20-100)$ \\
\hline Maternal sleep adequacy (post-test)* & 51.70 & 21.40 & $(20-90)$ \\
\hline Maternal quantity of sleep in hours (pretest) & 6.29 & 1.14 & $(4-8)$ \\
\hline Maternal quantity of sleep in hours (post-test) & 6.91 & 0.87 & $(5-9)$ \\
\hline Maternal sleep disturbances (pretest) $\dagger$ & 52.72 & 12.71 & $(16-75)$ \\
\hline Maternal sleep disturbances (post-test) $\dagger$ & 62.60 & 9.70 & $(40-81)$ \\
\hline Maternal perception of infant sleep problems (pre-test)† & 2.36 & 0.56 & $(1-3)$ \\
\hline Maternal perception of infant sleep problems (post-test) $\dagger$ & 2.76 & 0.45 & $(2-3)$ \\
\hline \multicolumn{4}{|l|}{ Mother-infant emotional availability variables } \\
\hline Mutual attunement (pre-test) & 27.81 & 5.72 & $(12-38)$ \\
\hline Mutual attunement (post-test) & 30.22 & 3.91 & $(22-36)$ \\
\hline Child involvement (pre-test) & 24.91 & 6.21 & $(11-36)$ \\
\hline Child involvement (post-test) & 28.91 & 4.50 & $(22-36)$ \\
\hline Affect quality (pre-test) & 17.52 & 1.95 & $(13-20)$ \\
\hline Affect quality (post-test) & 18.35 & 1.62 & $(15-20)$ \\
\hline Intrusiveness (pre-test) & 12.99 & 3.17 & $(6-18)$ \\
\hline Intrusiveness (post-test) & 13.75 & 2.42 & $(8-20)$ \\
\hline Hostility (pre-test) & 4.59 & 4.54 & $(0-18)$ \\
\hline Hostility (post-test) & 3.11 & 3.54 & $(0-15)$ \\
\hline
\end{tabular}

Note. *Higher values represent lower adequacy, i.e., more problems. †Higher values represent less problems.

\subsection{Maternal sleep patterns}

Although there was no statistically significant change over time in maternal sleep patterns, $\mathrm{F}_{W i l k^{\prime} \operatorname{sLambda}}(3,20)=$ $1.20, p=.34, \eta^{2}=.15$, based on means, the change was in the expected direction. Infant age was not significant as a Published by Sciedu Press covariate.

\subsection{Maternal perceptions of infant sleep}

Although there was no statistically significant change over time in perceptions of infant sleep, $\mathrm{F}(1,22)=.09, p=.77$, $\eta^{2}=.004$, based on means, the change was in the expected 
direction. Infant age was not significant as a covariate.

\subsection{Emotional availability}

In accordance with our hypothesis, there was a main effect of time, $\mathrm{F}_{W i l k^{\prime} \text { L Lambda }}(5,18)=5.27, p=.004, \eta^{2}=.59$, suggesting that the mother-infant relationship quality improved over time which was potentially related to the intervention. Univariate tests indicated that EA mutual attunement, F (1, $22)=5.37, p=.03, \eta^{2}=.20$, EA maternal hostility, $\mathrm{F}(1,22)$ $=8.36, p=.008, \eta^{2}=.28$, and child involvement, $\mathrm{F}(1,22)$ $=5.24, p=.032, \eta^{2}=.19$, all showed improvements from pre- to post-intervention. Infant age was not significant as a covariate.

\section{Discussion}

The purpose of the current study was, first, to assess the feasibility of easily recruiting, adequately delivering, and sufficiently retaining participants for the Possums curriculum implementation in a group setting and secondarily, to evaluate the intervention in improving participants' sleep patterns, and reported emotional availability in the mother-infant relationship.

Recruitment proved far more challenging than we had anticipated, and likely this may have had to do with the group administration of the program as previous reports do not indicate this. Conflict with prior work and family commitments were reoccurring themes for potential participants choosing not to participate. To address this issue, we added two weekday workshops in addition to weekend workshops. In hindsight, offering workshops on various days and times may have improved our recruitment rates. The lack of success in recruiting from a large pediatric office was also surprising, given that infant sleep problems are the most common pediatric complaint. ${ }^{[41]}$ To address this barrier, it is worth contemplating creating workshops that are delivered via video conferencing platforms such as Skype or Zoom. To supplement the video conferencing options, further workshops might include a Facebook page or discussion board where participants can engage when it is convenient for them. This has the potential of also benefiting women whose busy schedules are in conflict with in-person groups.

Our most successful recruitment locations were a local new mothers' group and the Facebook page associated with the group. The success of these two sites may be related to the fact that same the facilitator of the mother's group conducted the Possums workshops. Prior personal knowledge of the facilitator may have positively influenced recruitment, indicating that it may be useful in future studies to do more groundwork in multiple local clinics or perhaps have their personnel conduct the recruitment.
The existing controversy regarding infant sleeping arrangements ${ }^{[33,42]}$ may have contributed to recruitment difficulties. From the perspective of the investigators, the recruitment material did not align with any specific infant sleep paradigms; however, potential participants who may not have subscribed to behavioral sleep interventions or the AAP's ${ }^{[43]}$ recommendation against bed sharing may have interpreted the study as one that promotes these methods; therefore, choosing not to participate. On the other hand, the phrase "emotionally available caregiving" may have alienated those parents who practice various forms of delayed response to infant distress. To avoid unintentionally alienating potential participants, further recruitment efforts should begin with a review of the recruitment materials (e.g., flyers, websites, social media platforms, discussion boards) by a multidisciplinary team to ensure that the language of all resources is viewed as health promotive, culturally sensitive and inclusive. Individuals' comfort with group workshops is another area to investigate further in terms of recruitment difficulties, as this was, to our knowledge, the first effort to use the intervention in a group format.

Although our attrition rate was low, it is important to note that one participant withdrew related to concerns of time commitment required in addition to also attempting to establish a nursing and sleep routine for her 3 -week old infant. It is possible that these types of interventions would be more feasible for mothers of slightly older infants, who already have established the basic routines.

In line with a previous qualitative study from Australia where participants found the intervention highly acceptable and valuable, ${ }^{[35]}$ the participant engagement was also high in our study. Building a strong relationship between the facilitator and group members was emphasized, which may have helped these women feel safe to share their frustrations and triumphs regarding their infant's sleep and want to actively engage in such discussions.

An unexpected and delightful strength of the Possums program is its potential to build and strengthen relationships: relationships among the women and relationships between the women and their children. Although the study design did not incorporate a measure that assessed participant connectedness with one another, anecdotally, the women in the study tended to build supportive friendships. In the case of one cohort, a year after the completion of the study these seven women still arrange regular playdates with one another. In terms of the relationship between the mother and child, the Possums Intervention may actually strengthen their emotional relationship, based on maternal reported emotional availability. 
Findings regarding the effectiveness of the Possums curriculum were mixed. While the results did not show statistically significant improvements in maternal or infant sleep over time, there were non-significant changes in the positive direction in both. It is possible that with a larger sample size, the positive effects on maternal and infant sleep would have been significant. Furthermore, the Possums Intervention did improve parent-child relationship quality, as perceived by the mother. It is also possible that the intervention was not as effective on infant sleep due to the young age of infants, since infants younger than six months often do not yet have regular sleep cycles and may still need nighttime feedings. ${ }^{[44]}$ To address this, in the future, the intervention should be specifically tested with different age groups.

\section{Limitations}

With regard to the evaluation of the Possums curriculum, it is important to recognize the limitations with the study, foremost the absence of a control group. Without a control group to compare to, it is impossible to assess whether significant changes or lack thereof, in maternal sleep patterns, perceptions of infant sleep and reported emotional availability are due to the intervention, the progression of time, or developmental changes within the infant. As previously discussed, infant sleep is a complex developmental process that both progresses and regresses over the first year depending on where the child is developmentally. Positive or negative changes in the amount of sleep a mother receives each night may be due to her infant's newfound ability to sleep in more concentrated segments throughout the night allowing the mother to achieve longer periods of sleep. In the same vein, a mother's sleep may be compromised as her infant learns to stand in the crib but does not have the skill to sit back down on his/her own, causing the infant to cry out for help. The progression of time must also be considered. For example, a mother's self-efficacy may increase due to more time in her role as a mother rather than any effects of the intervention.

The use of self-report measures to assess maternal and infant sleep patterns and emotional availability, is another limitation of the evaluation. Observational and behavioral (e.g., actigraph) data collection would reduce measurement biases. The small sample size is a substantial limitation to the study. A sample size of 24 decreases the statistical power of the findings, ${ }^{[45]}$ which limited the investigators' ability to detect findings that may be practically or clinically important and may have hindered reaching statistically significant results related to improvements in maternal and infant sleep. Increased efforts during the recruitment stage would be beneficial in increasing the sample size.

\section{Conclusions}

In summary, the current study is the first to evaluate the feasibility of recruiting, implementing, and retaining participants in Possums group workshop. The findings indicate that once participants are recruited, Possums can be successfully implemented in a group setting with high participant engagement and low attrition rates. Further studies that include both an intervention and a control group are needed to evaluate whether changes in maternal and infant sleep patterns and mother-infant interaction exist and whether they are due to the intervention. It is fascinating that while the intervention improved the intended outcomes only on a trend level, it appears to have had a clear positive effect on the quality of emotional availability in the relationship, at least as perceived by mothers. As such, the intervention appears to have a positive effect on the environment that supports good sleep. The intervention should also be tested in multiple cultures: It was originally developed in Australia, where maternity leaves are longer than in the US, perhaps diminishing the need to get infants to sleep through the night from very early on, which may also affect parental intervention preferences and experiences of the intervention.

\section{ACKNOWLEDGEMENTS}

We thank the study families for the their time and dedication to this project.

\section{CONFlicts of InTEREST Disclosure}

Author ZB has disclosed a potential financial conflict of interest because she developed the Emotional Availability (EA) Self Report used in this paper and potentially stands to gain from favorable outcomes in studies. Because of this possibility, Biringen voluntarily distances herself from primary handling of data and analyses. Biringen has a conflict of interest management plan supervised by Colorado State University.

\section{REFERENCES}

[1] Hunter LP, Rychnovsky JD, Yount SM. A selective review of maternal sleep characteristics in the postpartum period. JOGNN - Journal of Obstetric, Gynecologic, and Neonatal Nursing. 2009 Jan-Feb;
38(1): 60-68. PMid:19208049 https ://doi.org/10.1111/j.15 $52-6909.2008 .00309 . x$

[2] Vandekerckhove M, Kestemont J, Weiss R, et al. Experiential versus analytical emotion regulation and sleep: Breaking the link be- 
tween negative events and sleep disturbance. Emotion. 2012 Dec; 12(6): 1415-1421. PMid:22775124 https://doi.org/10.1037/ a0028501

[3] Walker MP. The role of sleep in cognition and emotion. Annals of the New York Academy of Sciences. 2009 Mar; 1156: 168-197. PMid:19338508 https://doi.org/10.1111/j.1749-6632. 20 09.04416.x

[4] Meltzer LJ, Mindell JA. Relationship between child sleep disturbances and maternal sleep, mood, and parenting stress: A pilot study. Journal of Family Psychology. 2007 Mar; 21(1): 67-73 PMid:17371111 https://doi.org/10.1037/0893-3200.21.1 .67

[5] Goyal D, Gay C, Lee K. Fragmented maternal sleep is more strongly correlated with depressive symptoms than infant temperament at three months postpartum. Archives of Women's Mental Health. 2009 Aug; 12(4): 229-37. PMid:19396527 https://doi.org/10.100 7/s00737-009-0070-9

[6] Hiscock H, Cook F, Bayer J, et al. Preventing early infant sleep and crying problems and postnatal depression: a randomized trial. Pediatrics. 2014 Feb; 133(2): e346-54. PMid:24394682 https: //doi.org/10.1542/peds. 2013-1886

[7] Wake M, Morton-Allen E, Poulakis Z, et al. Prevalence, stability, and outcomes of cry-fuss and sleep problems in the first 2 years of life: prospective community-based study. Pediatrics. 2006 Mar; 117(3): 836-42. PMid:16510665 https : //doi .org/10.1542/peds . 200 5- 0775

[8] Willinger U, Diendorfer-Radner G, Willnauer R, et al. Parenting stress and parental bonding. Behavioral Medicine (Washington, D.C.) 2005 Summer; 31(2): 63-9. PMid:16130308 https://doi.org/ 10.3200/BMED . 31 . 2.63-72

[9] Blampied NM, Bootzin RR. Sleep - a behavioral account. In G. Madden (Ed.), The Handbook of Behavior Analysis. Washington, D.C.: American Psychology Association. 2011.

[10] Cassels T, Ockwell-Smith S, Middlemiss W, et al. Is your baby's sleep a problem? Or is it just normal? Motherbaby sleep experts weigh in on normal infant sleep (White Paper). 2013. [Cited 2015 Feb 1]. Available from: http://praeclaruspress. com/wp-content/uploads/2013/ 08/praeclarus-press-normal-infant-sleep-2.pdf

[11] Sadeh A, Tikotzky L, Scher A. Parenting and infant sleep. Sleep Medicine Reviews. 2010 Apr; 14(2): 89-96. PMid:19631566 https: //doi.org/10.1016/j.smrv.2009.05.003

[12] Skinner BF. Science and human behavior. New York, NY: Macmillan. 1953.

[13] Burnham MM, Goodlin-Jones BL, Gaylor EE, et al. Nighttime sleep-wake patterns and self-soothing from birth to one year of age: a longitudinal intervention study. Journal of Child Psychology and Psychiatry. 2002 Sep; 43(6): 713-725. PMid:12236607 https://doi.org/10.1111/1469-7610.00076

[14] DeLeon CW, Karraker KH. Intrinsic and extrinsic factors associated with night waking in 9-month-old infants. Infant Behavior and Development. 2007 Dec; 30(4): 596-605. PMid:17416420 https://doi.org/10.1016/j.infbeh.2007.03.009

[15] Sadeh A, Mindell JA, Luedtke K, et al. Sleep and sleep ecology in the first 3 years: a web-based study. Journal of Sleep Research. 2009 Mar; 18(1): 60-73. PMid:19021850 https://doi.org/10.1111/ j.1365-2869.2008.00699.x

[16] Tikotzky L, Sadeh A. Maternal sleep-related cognitions and infant sleep: A longitudinal study from pregnancy through the 1st year. Child Development. 2009 May-June; 80(3): 860-874 PMid:19489908 https://doi.org/10.1111/j.1467-8624.20 $09.01302 . \mathrm{x}$
[17] Douglas PS, Hill PS. Behavioral sleep interventions in the first six months of life do not improve outcomes for mothers or infants: A systematic review. Journal of Developmental and Behavioral Pediatrics. 2013 Sep; 34: 497-507. PMid:24042081 https: //doi.org/10.1097/DBP.0b013e31829cafa6

[18] Mindell JA, Kuhn B, Lewin D, et al. Behavioral treatment of bedtime problems and night wakings in infants and young children. Sleep. 2006 Oct; 29(10): 1263-1279. https://doi.org/10.1093/slee $\mathrm{p} / 29.10 .1263$

[19] Hill C. Practitioner review: effective treatment of behavioural insomnia in children. Journal of Child Psychology and Psychiatry, and Allied Disciplines. 2011 Apr; 52(7): 731-40. PMid:21501164 https://doi.org/10.1111/j.1469-7610.2011.02396.x

[20] Whittingham K, Douglas P. Optimizing parent-infant sleep fro birth to 6 months: A new Paradigm. Infant Mental Health Journal. 2014 Nov-Dec; 35(6): 614-23. PMid:25798510 https ://doi.org/10 $.1002 / \mathrm{imhj} .21455$

[21] Blunden S, Baills A. Treatment of behavioural sleep problems: Asking the parents. Journal of Sleep Disorders: Treatment and Care. 2013 Jun; 2(2): 1-7. https://doi .org/10.4172/2325-9639.100011 0

[22] Galland BC, Taylor BJ, Elder DE, et al. Normal sleep patterns in infants and children: a systematic review of observational studies. Sleep Medicine Reviews. 2012 Jun; 16(3): 213-22. PMid:21784676 https://doi.org/10.1016/j.smrv.2011.06.001

[23] Henderson JMT, France KG, Blampied NM. The consolidation of infants' nocturnal sleep across the first year of life. Sleep Medicine Reviews. 2011 Aug; 15(4): 211-20. PMid:21051245 https://doi. org/10.1016/j.smrv.2010.08.003

[24] St James-Roberts I, Morris S, Owen C, et al. Use of a behavioural programme in the first 3 months to prevent infant crying and sleeping problems. Journal of Paediatrics and Child Health. 2001 Jun; 37(3): 289-297. PMid:11468047 https://doi.org/10.1046/j. 1440-1754.2001.00699.x

[25] Symon BG, Marley JE, Norman ER. Effect of a consultation teaching behaviour modification on sleep performance in infants: A randomized controlled trial. Medical Journal of Australia. 2005 Mar; 182(5): 215-218. PMid:15748130 https : //doi.org/10.5694/j. 1326-5377. 2005.tb06669. $x$

[26] Stremler R, Hodnett E, Kenton L, et al. Effect of behaviouraleducational intervention on sleep for primiparous women and their infants in early postpartum: multisite randomised controlled trial. BMJ (Clinical Research Ed.). 2013 Feb; 346: f1164. PMid:23516146 https://doi.org/10.1136/bmj.f1164

[27] Dørheim SK, Bondevik GT, Eberhard-Gran M, et al. Sleep and depression in postpartum women: a population-based study. Sleep. 2009 July; 32(7): 847-55. PMid:19639747 https ://doi.org/10 $.1093 / \mathrm{sleep} / 32.7 .847$

[28] Iacovou M, Sevilla A. Infant feeding: the effects of scheduled vs. on-demand feeding on mothers' wellbeing and children's cognitive development. The European Journal of Public Health. 2013 Feb; 23(1): 13-19. PMid:22420982 https://doi .org/10.1093/eurp $\mathrm{ub} / \mathrm{cks} 012$

[29] Ball HL. Supporting parents who are worried about their newborn's sleep. BMJ (Clinical Research Ed.). 2013 Apr; 346: f2344. PMid:23587748 https://doi .org/10.1136/bmj .f2344

[30] Blunden SL, Thompson KR, Dawson D. Behavioural sleep treatments and night time crying in infants: challenging the status quo. Sleep Medicine Reviews. 2011 Oct; 15(5): 327-34. PMid:21295501 https://doi.org/10.1016/j.smrv.2010.11.002

[31] Whittingham K, Douglas P. The possums sleep intervention: First six months. 2014. 
[32] Scammon R, Doyle L. Observations on the capacity of the stomach in the first ten days of postnatal life. American Journal of Diseases of Children. 1920 Dec; 20(516-538). https ://doi .org/10.100 1/archpedi.1920.01910300056005

[33] McKenna JJ, McDade T. Why babies should never sleep alone: a review of the co-sleeping controversy in relation to SIDS, bedsharing and breast feeding. Paediatric Respiratory Reviews. 2005 Jun; 6(2): 134-52. PMid:15911459 https ://doi .org/10.1016/j .prrv. 2 005.03 .006

[34] Douglas PS. The Possums Program: Supporting easy, healthy parentinfant sleep. International Journal of Birth and Parent Education. 2018; 6(1): 13-16.

[35] Ball HL, Douglas PS, Kulasinghe K, et al. The Possums Infant sleep program: Parents' perspectives on a novel parent-infant sleep intervention in Australia. Sleep Health. 2018 Dec; 4(6): 519-526. PMid:30442320 https://doi.org/10.1016/j.sleh.2018.08 .007

[36] Hays RD, Martin SA, Sesti AM, et al. Psychometric properties of the Medical Outcomes Study Sleep measure. Sleep Medicine. 2005 Jan; 6(1): 41-4. PMid:15680294 https://doi.org/10.1016/j.slee p. 2004.07.006

[37] Hays RD, Stewart AL. Sleep measures. In A. L. Stewart J. E. Ware (Eds.), Measuring functioning and well-being: The Medical Outcomes Study approach. Durham, NC: Duke University Press; 1992; 235-259.
[38] Sadeh A. A Brief Screening Questionnaire for Infant Sleep Problems: Validation and Findings for an Internet Sample. Pediatrics. 2004 Jun; 113(6): e570-e577. PMid:15173539 https://doi.org/10.1542/ peds.113.6.e570

[39] Biringen Z, Vliegen N, Bijttebier P, et al. The Emotional Availability Self-Report. 2002. Available from: www.emotioanlavailability.com.

[40] Vliegen N, Luyten P, Biringen Z. A multimethod perspective on emotional availability in the postpartum period. Parenting. 2009; 9(3-4): 228-243. https://doi.org/10.1080/15295190902844514

[41] Ferber R. Sleepless child. In C. Guilleminault (Ed.), Sleep and its disorders in children. New York: Raven Press; 1986; 141-163.

[42] Mileva-Seitz VR, Bakermans-Kranenburg MJ, Battaini C, et al. Parent-child bed-sharing: The good, the bad, and the burden of evidence. Sleep Medicine Reviews. 2017 Apr; 32: 4-27. PMid:27107752 http://doi.org/10.1016/j.smrv. 201 6.03 .003

[43] Moon RY. SIDS and Other Sleep-Related Infant Deaths: Evidence Base for 2016 Updated Recommendations for a Safe Infant Sleeping Environment. Pediatrics. 2016 Nov; 138(5): e20162940-e20162940. PMid:27940805 http://doi .org/10.1542/peds . 2016-2940

[44] AAP sleeping guide. Available from: https://www .healthychi ldren.org/English/ages-stages/baby/sleep/Pages/Get ting-Your-Baby-to-Sleep. aspx

[45] Cohen J. Statistical power analysis for the behavioral sciences (Rev). New York: Academic Press; 1988. 